\title{
$\mathrm{G}-1-3$ 触運動覚による指先移動量の知覚
}

\section{Length Perception Characteristics via Fingertip Cutaneous Sensationr}

\author{
○学 岩部和樹（三重大院） 正 野村由司彦（三重大院） \\ 正 Syed Muammar Najib Syed Yusoh（三重大院）坂本良太（三重大病院） \\ Kazuki Iwabu, Mie University, 1-1 Kikai-cho, Nagoya 000-0001, Japan \\ Yoshihiko Nomura Mie University, 1-2 Kikai-cho, Nagoya 000-0002, Japan \\ Syed Muammar Najib Syed Yusoh, Mie University , 1-3 Kikai-cho, Nagoya 000-0003, Japan \\ Ryota Sakamoto, Mie University
}

\begin{abstract}
Line length perceptual characteristics have been studied from various viewpoints: for example, the person's initiative in the movements, and the sensations such as the proprioceptive sensations that return the physical states of joint rotations, the muscle activity sensations with extension and flexion, and the cutaneous sensations. However, in the existing works, there have been limited within specific aspects. Therefore, from the viewpoints of covering the above-described factors generally, two-dimensional line segment perceptual characteristics were examined by using a 2-D Cartesian coordinate liner actuator. The Line length perceptual characteristics shall be applied to line drawing presentation systems for visually impaired persons in the future.
\end{abstract}

Key Words: Length Perception Characteristics factor effect

\section{1. 緒言}

視覚と触覚により並列的に外界の情報を入手し，これを 処理・解析し，外界を認識・理解することは，視覚健常者 にとってはあまりにも当然のことであり，そのことの重要 性に気付きにくい. しかし，視覚障碍者にとって図形の認 識はきわめて困難であり，そのための不自由は計り知れな い. 我々は, この問題を解決すべく. 視覚に代わる感覚器 として，触覚を活用し. 図形認識を支援するシステムの開 発を目指して研究を進めてきた。

触覚は 2 次元で主な体に分布する感覚器を用いることか ら，その情報に基づいて，パターン認識できる可能性は残 っている. とはいえ，パターンを一気に提示することは困 難であり，対象を㨨でて認識することが，当面の課題であ ろう。つまり，蝕運動覚を通して時系列的に入力される手 先, 指先の位置の情報を連接させて 2 次元のパターンを認 識することが当面の方策として有力であると考えられる.

本研究は，このような趣旨で着手したものであり，まず は，触運動覚を通して効率的に，そして効果的に線画が認 識できるシステムの構築を目指している．その観点で，触 覚(haptic perception)による線分知覚の研究に関しては, 現在まで，提示図形と身体との位置関係，提示する線分の 属性, 動作に関する使用者の主体性の有無, 表面性状, 提 示速度に関して行われてきたが，多くは限定された条件に 限られており，知覚特性は包括的に調べられているとは言 えない，このような状況を踏まえ，線図形の認識を支援す るシステムの開発の一助とすべく, 本研究は, 触運動覚に よる線図形の知覚特性を包括的に検討したものである.

具体的には，二つの直動型アクチュエータを直交座標型 に組み合わせることにより，2 次元的な線分の提示を可能 とし, これを用いて, 多様な条件で包括的に心理物理実験 を実施してヒトの線分の知覚特性を調查した.

\section{2. 従来の研究のまとめ}

触覚 (haptic perception)による線分の長さの知覚のモ ードは，大まかには，二つの視点から分類できる．第一の 分類の視点は, 用いる感覚器の種類である.すなわち, 用 いる感覚器は,

（1）指先の指腹部を用いる皮膚感覚 (cutaneous sensation) (実験では主に人差し指(示指)が用いられることが多い)

(2) 関節と筋肉の状態 (joint totation and mustle expansion and contraction)の受容器によ る身体動作感 覚 (固有感覚, proprioceptive sensation),

(3) 各種の皮膚感覚と固有感覚の両者を統融合した触運動 知覚 (Combined perception).

の三つに分類できる.

さらに, 線分の知覚という観点では, 皮膚感覚 (cutaneous sensation）においては, 隆点, 隆縁, 溝などの表面の凹凸 に対す厓覚と，指腹部表面之対象物体表面との相対的な 滑りに関ずる滑り覚(slip sense)が重要である. 前者から は輪郭の方向の情報を得ることができる．後者からは滑り 速度，ひいてはその積分值として長さの情報を得ることが できる.

これは, 線分の知覚は, 時々刻々, 指先で知覚した微小 な滑り量を累積するような形で，すなわち滑り速さを時間 について積分するような形で, 知覚しているものと考えら れる.ここで, この微小な滑り量, 寸なわち滑り速さであ るが，平面の場合には，滑りに伴って発生する自励振動の 周波数や振幅，さらにはせん断ひずみなど，指腹部にある 多様な皮膚感覚からの情報を統合して知覚しているものと 思われる. しかし，これらの情報は指の押付力，指と平面 との動摩擦係数などの要因にも影響されることから，滑り 長さの知覚は滑り速さの一価関数にはなりえない.もし, 純粋な平面ではなく，釣鐘形状に浮彫り加工した凹凸面を 滑らせた場合には, 滑りはどのように知覚されるのか?凸凸 面の場合，知覚した振動の周波数と経過時間 (duration time) とを加味することにより滑り覚 (slip sense)をより 正確に知覚でき, 滑り長さもある程度の精度で知覚できる ものと期待される. 加えて, 滑りに際して,「凹凸により局 
所的に変形している領域が移動している」と感じるような 形の “接触点運動知覚” も生じ, これも滑り長さの知覚に 大きく寄与すると考えられる.

また，身体動作感覚 (proprioceptive sensation) にお いては, 手先や指先などの効果器 (end effector) とそれら が触れている対象物体との間の相互作用としての指・手 首・前腕・上腕・肩などの上半身の関節を駆動する筋肉 力覚,およびそれらの関節の回転角度の感覚が重要である. 前者を通して, 力覚フィードバックシステムから輪郭の方 向の情報を得ることができる．また，後者からは輪郭追跡 時の時々刻々の関節角度の情報の積分值として, 輪郭の軌 跡（長さも含む）の情報を得ることができる.

第二の分類の視点は, 被験者と外界 (輪郭呈示物体や力 覚フィードバックシステムなど）との間の主導権 (initiative) の方向性である。すなわち，主導権 (initiative)の方向性は,

(1) 受動 (passive touch)

(2) 能動 (active touch)

の二つに分類できる.

受動（passive touch）においては，被験者は自らの意思 とは無関係に外界から一方的に情報を送られ，送られた情 報に基づいて輪郭の形状を推定する.

一方, 能動（active touch）においては，被験者は自らの意 思に基づいて探索を行い，その結果として獲得した情報に 基づいて輪郭の形状を推定するものである，

触覚による線分の長さの知覚のモードは, したがって, こ れらの二つの視点の積事象としてとらえることができる. すなわち, 皮膚感覚 (cutaneous sensation) については受 動 (passive touch) しか考えられないことに注意すると， $\mathrm{CuPa}$ (cutaneous passive)

$\mathrm{PrPa}$ (proprioceptive passive)

$\mathrm{CoPa}$ (combined passive)

PrAc (proprioceptive active)

CoAc (combined active)

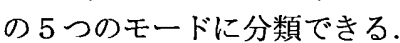

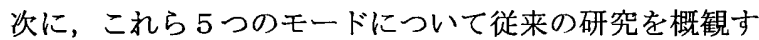
る.まず，触覚 (haptic perception)による線分の知覚の研 究は, 歴史的に見て研究の初期段階では, Raised dots/ Raised edge/ Raised figure/ Slot/ Ditch/ Rod などの物 理的な長さを有する物体を用い，これをなぞる (touch and slide)ことから始まっている. そのため, CoAc (combined active)のモードをベースとして, 線分知覚特性の研究は数 多くなされてきた.

すなわち, 長さについては, 多くの条件で縮減効果が認め られているが, 特に, 運動速度増大に伴う縮減増大効果 (1986, B. L. Whitse1, , 1988, M. Hollins) は重要であ る[1].

また，身体との相対位置による位置の知覚の歪みについ ても, 前額平行面 (frontal parallel plane)に対する方向 の違いによる縮隇効果の異方性として, 多く研究されてい る (1968, Cheng, 1970, Day) [2] [3]. さらに, 同異方性 の要因についても研究されており, 多くは腕の動作の半径 方向（回内/回外）と接線方向（屈曲/伸展）とで腕の慣性 の違いにあると言われているが，負荷実験によりその影響 がほとんど見られないとの指摘 (1983, Marchetti \& Lederman) もある [4].

また，同じく要因として，経過時間 (duration time) の影 響の重要性についても指摘（1999, Laura Armstrong）され ている [5]. 運動速度が等しいという条件下では, 線分が長
いほど経過時間 (duration time) も大きくなるのは当然の ことであり, 経過時間 (duration time)が重要な情報源とな っていることは言うまでもない，これらの他にも経過時間 (duration time)の増大が影響していると思われるが, 迁回 路経由時の両端点間距離の過大評価 (1985, Lederman) (Exp Brain Res (2003)) Faineteau aiEdouard Gentaz entaz GViviani, The kinaesthetic perception of Euclidean distance: a study of the detour effect)についても研 究されている [6][7].

方向に関しては，(1936, Blumenfeld）は身体に近いほど 平行判断誤差が増大する傾向, 方向知覚には, 斜め条件で の誤差増大傾向 (oblique effect) (1980, Lechelt \& Verenka）が報告されている[8][9].

文字認識についてもよく調べられてきた。例えば, (1974J. M. Loomis)は CuPa (cutaneous passive) モードにお いて， 2 次元パターンとしてではなく， 1 次元パターンを 走査する形で呈示することが効果的であるとの知見を示し た[10]。また，(1991，F. Vega-Bermudez et al.) は実験条 件によりいずれのモードでも文字の識別性能には有意差は 認められないと報告している[11].

受動 (passive touch) と能動 (active touch)による知 覚特性の違いについては, 前額平行面に対する方向の誤差 が調べられており，能動 (active touch)は $3.4 \mathrm{c}$ であり, 受動 (passive touch)の 4. 9a に比して, 65\%まで低減する との報告がある.

近年においては, 電動直動駆動ステージや力覚フィード バックシステムなどの機械システムを活用して, 触覚 (haptic perception)により線分の長さ知覚特性について 研究されるようになってきた. 2006 には, Pierre Wydood が，力覚フィードバックシステムPhantomを用いて, PrPa (proprioceptive passive) と PrAc (proprioceptive active)について調查した[12]. その結果, 前者では長さを 過大評価し, 後者では過小評価するとの, 興味深い結果を 報告している．ただし，後者ではfully tracted の条件が 考慮されているにもかかわらず，前者では抵抗力を付与す る条件のみが調べられ，むしろ一般的と思われる，free active の条件が調べられていない点で, 研究の余地が残っ ていた．また，測定条件は断片的である点も引き続き研究 の余地が残っている.

同年には，寺田らも，電動直動駆動ステージを用いて, 受動 (passive touch)に関わる 3 モード, 寸なわち $\mathrm{CuPa}$ (cutaneous passive), $\mathrm{Pr} P a$ (proprioceptive passive), $\mathrm{CoPa}$ (combined passive)について，長さ・速度をパラメー タとした長さ知覚特性について, 調査している [13]. 寺田ら による $\mathrm{CoPa}, \mathrm{PrPa}, \mathrm{CuPa}$ では, (1986 Whitse1), と (1988 Hollins）と同样に速度による縮減効果が見られたが，その 程度は小さめな結果が得られた.さらには, CoAc (combined active) モードの知覚メカニズムについても研究を進め, Co と Pr, 複数の情報の融合が Maximum Operator (最大演算子) によってなされているとの興味深い知見を与えた.

直近では，(2011 Wouter)が, 左右方向で長さ $10 \mathrm{c} \mathrm{mだけ}$ という限られた条件下ではあるが，電動直動駆動ステージ を用いて, 感鸴器利用モードの 3 種すべての受動 (passive touch)について，すなわち CuPa (cutaneous passive), $\mathrm{PrPa}$ (proprioceptive passive), CoPa (combined passive)につ いて, 知覚特性を比較検討した。 その結果, 知覚誤差は $\mathrm{CuPa}<\mathrm{PrPa} \fallingdotseq \mathrm{CoPa}$, すなわち $\mathrm{CuPa}$ みが顕著に悪いこと, $\mathrm{CoPa}$ において, Pr が支配的であろうことを示晙する結果を報告 している. 
以上を概観寸ると，触覚 (haptic perception)による線分 知觉の研究は, 2000 年以前までは CoAc (combined active) モードをベースとしてヒトの長さ知覚特性が詳細に調べら れてきた. その後，2000 年以降では機械式アクチュエータ が導入されて, 受動 (passive touch) モードが扱われるよ うになり, 従来のPrAc, CoAc とは異なる切り口，すなわ

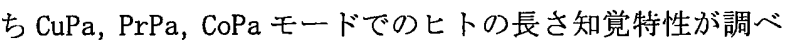
られるようになってきた. しかし，それらの研究の多くは，

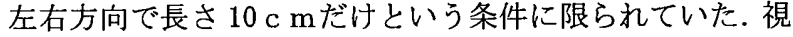
覚障碍者の図形認識を支援するシステムを開発するために は, 多様な方向, 多様な長さをカバーした，より一般的な 条件下で特性を確認する必要がある.

3. 因子効果評価実験 (知覚特性をモデル化するための実 験）

\section{1 概要}

本実験の目的は，線形モデル式作成のため，ヒトの知覚特 性を調査ずることである，そのために，知覚特性に影響を 与えると予測される因子の網羅的な調査が必要となる. ま た，それによる実験時間の増加，といった課題がある. 1 つ目の課題である, 知営特性に影響を与えると予測され る因子の網羅的な調查, については, 2 章で述べている様々 な要因を幅広く取り入れ，最適条件となる制御因子，特性 条件となる信号因子 2 つ因子に分けて選定し，これら因 子の水準を決定した．その中で，影響を及ぼす因子，そう でないものを事前に予備実験において評価を行い，取抒選 択した因子を因子効果評価実験で用いることにした．以上 の考えから，選定した因子を Table 1 にまとめる.

\section{Table 1 Classification of the factor}

\begin{tabular}{|l|l|}
\hline $\begin{array}{l}\text { Controllable } \\
\text { factor }\end{array}$ & Signal factor \\
\hline Sensation & Length \\
\hline Grating space & Angle \\
\hline & Speed \\
\hline & Subjects \\
\hline
\end{tabular}

制御因子に関しては，実験に用いる感覚器で因子を試験 面, 感覚の 2 つを因子として設定した.

皮膚感覚に関しては,

触運動知覚 (Combined perception)

身体動作感覚（固有感覚, proprioceptive sensation), の 2 つを水準として設定した. また，今後の研究が期待さ れるスタイラスを用いた線画提示装置などの開発に有効で あると考え，スタイラスの知覚特性も調查した。よめる と, 皮膚感覚においては,

示指+身体動作感覚,

スタイラス+身体動作感覚,

を設定したことになる.

また, 試験面に関しては, 圧覚と, 滑り覚の重要性を考 え,
平面 $(\mathrm{flat})$,

凸格子面 (grating space),

の 2 つを水準として設定した.

手の可動範囲を考慮して，試験面は，横 $350 \mathrm{~mm}$ ，縦 $550 \mathrm{~mm}$ とした．また，実際に使用されている点字のサイズに合わ せて，凸格子面の高さは $0.4 \mathrm{~mm}$ ，直径は $1.5 \mathrm{~mm}$ とした。格 子閒隔は点字の点閒距離内に収まる $3 \mathrm{~mm}$ 基準で設計した。 実際の実験では，格子間隔は，6mm, $24 \mathrm{~mm} の 2$ 種類を使用し た.

信号因子に関しては，実験で捉示する長さ，角度，速度 の 3 つを設定した.

これらの水準は,

長さに関しては, $25 \mathrm{~mm}, 50 \mathrm{~mm}, 75 \mathrm{~mm}, 100 \mathrm{~mm}, 125 \mathrm{~mm}, 150 \mathrm{~mm}$ ○) 6 水準,

角度に関しては，直交座標系の水平方向に右の方向を正 の向きにして反時計回りに，0，30，60，90，120，150，180, $210 ， 240 ， 270,300,330$ 関の 12 水準,

速度に関しては，13mm/s， $21 \mathrm{~mm} / \mathrm{s}, 65 \mathrm{~mm} / \mathrm{s}, 113 \mathrm{~mm} / \mathrm{s}$ ， $200 \mathrm{~mm} / \mathrm{s}$ の 6 水準を設定した.

また，実験は，全員健康に問題のない啨眼者の男性 12 名の被験者で行い，被験者の個々の系統誤の歪をモデル式 に加えることから，被験者は信号因子と設定した.

2 つ目の課題である，網羅的に実験を行うことによる実 験時間の増加に関しては，直交表を用い，各因子の水準を 組み合わせることにより，実験数を少なく節減した。すな わち，実験計画法における，1 セット 72 回の 1 因子 12 水 淮， 6 因子 6 水準， 3 因子 3 水準， 6 因子 2 水準に対する $L_{72}$ 直交表を利用して, 各因子の水準を組合せた実験条件を 設定した．さらに，各被験者に刘して，上記の 72 条件を 2 セット, 計 1728 (=72 回/セット $\times 2$ セット/人 $\times 12$ 人)で, 因子効果評価実験を実施した。

\section{2 実験装置}

実験装置の全体図を Figure 1に示す．大きく分けて 4 つ のデバイスで構成されている.

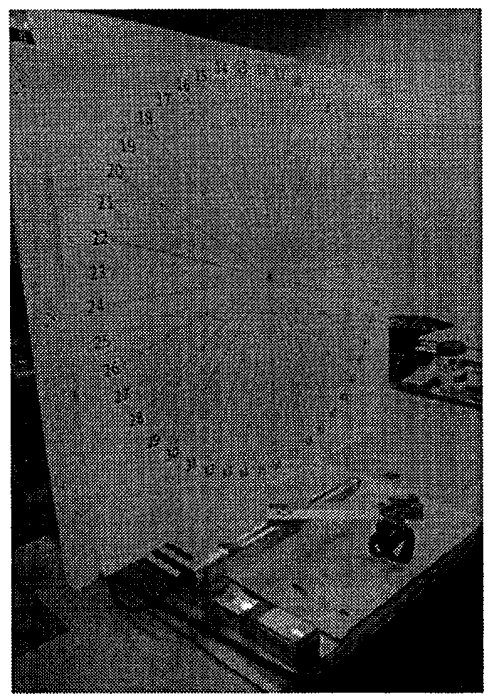

Figure 2 Experimental equipment

3.2.1 值動型駆動アクチュエータ 
実験では, 直動型アクチュエータ(IAI-ICSA シリーズ)を直 交して連結し, 被験者の指先を 2 次元的に動かせるようにした。 短軸側の滑り子には, 治具を介して, 指先を誘導するための手 拘束バンドが取り付けられている.

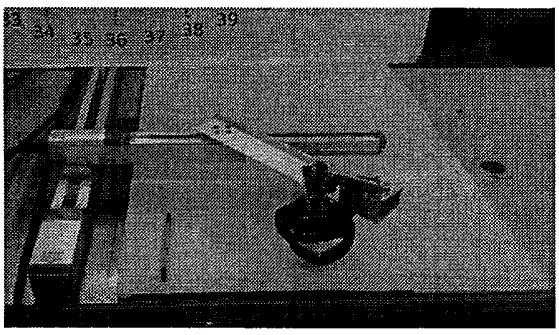

Figure 3 Liner actuator

\section{2 .2 拘束バンド}

ペンを持つようにして，自然にスタイラスが持てるよう，手の甲 の角度を変更できる機構となっている.
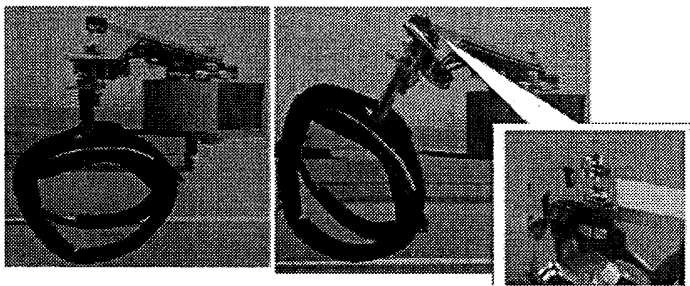

Figure 4 Restriction band

\subsection{3 実験用スタイラス}

長さ $145 \mathrm{~mm}$ のスタイラス筐体の先端には, 直径 $4 \mathrm{~mm}$ のプ ラスチック球を取り付けた。

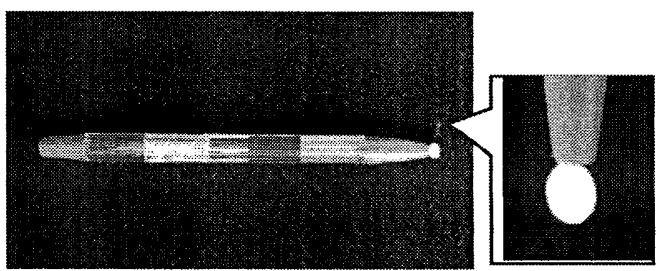

Figure 5 Experimental stylus

\section{2 .4 回答ボード}

提示線分の最大值が $150 \mathrm{~mm}$ であることから, 回答ボードの 半径はその 2 倍の $300 \mathrm{~mm}$ とした. 角度は $7.5^{\circ}$ 単位, 長さは $5 \mathrm{~mm}$ 単位で回答できるようにした. 被験者は, 水平面上で知 覚した線分のメンタルイメージを,この鉛直に揭示した回答ボー ド上に座標変換することで回答を行った。

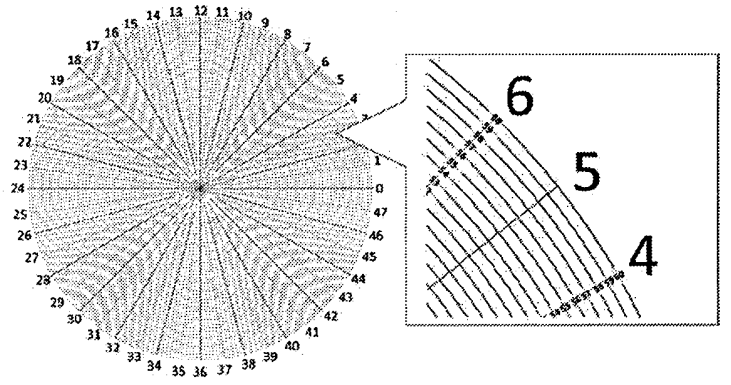

Figure 6 Answer board

\section{2 .5 感覚}

運動感覚 (手・肘・肩関節, スタイラスを利用), 皮膚感 覚 (示指の指腹部) +運動感覚 (手・肘・肩関節) の $2 つ 0$ 感覚で比か特性を比較した。
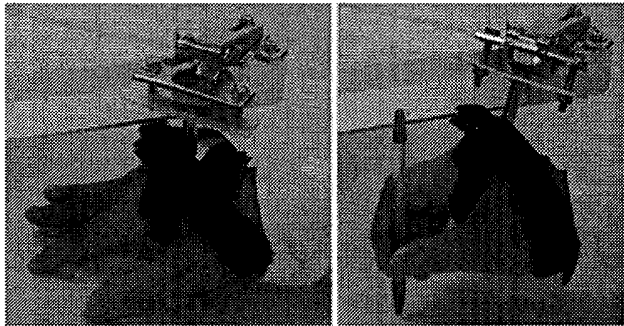

Figure 7 Sensation

\section{2 .6 被験者}

被験者は, 腕の旋回が $0^{\circ}$ のとき, 肩を通り, 矢状面(左右真 二つに身体を切断する面)に平行な面内に位置するように, 腕 の伸展の位置が $225 \mathrm{~mm}$ において, 上腕が鉛直かつ肘関節の 屈曲が $90^{\circ}$ となるような位置で手を拘束バンドで固定した. 実 験中は, ヘッドフォンを着用し, ホワイトノイズを流して行った。 なお, 被験者の目線と回答ボード間の距離を $50 \mathrm{~cm}$ に統一す るために顎当て (chin rest)を使用した.

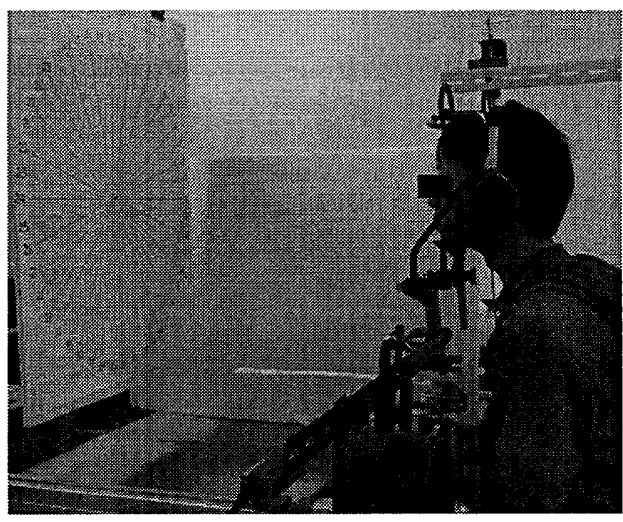

Figure 8 Subjects

\section{4. 実験方法}

被験者は, リラックスして椅子に座り, 右腕の前腕部を水平か つ前額平行面に平行な方向に構え，右手を実験装置に装着 する. 
その後,

(1) 試験面の設定:実験者が実施,

(2) 感覚の設定:実験者の音声による指示にしたがって, 被 験者が行う

の順に各因子の水準を決定する.

次に,

(3) 実験者のキーインによりリニアアクチュエータが被験者 ○腕 (手, 指を含む)を誘導し，ランダムに設定された始 点の設定へ誘導する.

以下，捉示した線分ごとに繰り返す。

(4) 実験者による「開始」の合図とともに, アクチュエータが 始点から終点に向けて被験者の手(指)を誘導する. 被 験者は, 自らの運動に関する刺激を運動感覚で受容・ 知覚するとともに, 示指またはスタイラスを介して得られ る試験面からの刺激を皮膚感覚で受容·知覚し，提示さ れた場所に知覚した線分のメンタルイメージを脳内で想 い描く.

(5) 被験者がアクチュエータの動作の停止を知覚したとき, 知覚した線分を回答ボードが存在していると想定される 位置に座標変換する。.その後, 被験者は目を開き, 知 覚した線分に相当する, 回答ボード上の参照目盛を見 て, 角度, 長さの順に回答する.

なお，実験中は，被験者は目を閉じている状態で実験を行 った. また, アクチュエータの音量により速さを推定し, 長さ知覚 に影響を与えることのないように, ヘッドフォンを装着し, 白色雑 音を聞かせた。

\section{5. 実験結果}

制御因子の各因子における, 長さ知覚, 角度知覚の系統誤 差, 偶然誤差に関する分散分析, 等分散検定をまとめたものを Table 2に示す. 分散分析より, 試験面因子, 感覚因子, いずれ の制御因子においても，長さ知覚に関しては水準間に差のあ ることが, 判明した. ただし, 角度知覚においては, 試験面因子 の因子効果には有意差は認められなかった. また, Bartlettの 等分散検定から, 試験面の不等分散性はわずかにしか見られ なかった. ゆえに, 試験面においては, Figure 9より長さ効果の 系統誤差が 0 に近い值を示している「格子面 $6 \mathrm{~mm}$ 水準」が比 較的優れた性能を示していると考えられる.

また，感覚因子においては，長さ知覚，角度知覚，ともに $1 \%$ 水準で有意であることが分散分析でも，Bartlett の等分散検 定でも明らかになった.これは, Wouter[14]の実験で示された 「触覚の追加は特に長さ知覚の特性の改善に効果があるとは いえないとの結果とは異なった.この結果に関して, 因子効果 評価実験では，提示速度条水準をより細かく設定しており，特 に, 長さ知覚の難易度は上昇している. そのため, 従来の粗い 実験では現れなかった有意差が顕著になった可能性などが考 えられる.なお，本来ならば交互作用の効果を調查する必要性 もあるが，今回の実験においては，総当たりではなく，実験計 画法による直交表を用いることで, 実験の組み合わせを極端に 絞り込んでおり，交互作用を調べることは出来なかった.この点 においては実験法の改善の余地が残っている

Table 3 ANOVA table on reproduction errors and Bartlett test for variance homogeneity : Controllable factor

\begin{tabular}{|l|l|l|l|l|}
\hline $\begin{array}{l}\text { Controllable } \\
\text { factor }\end{array}$ & $\begin{array}{l}\text { Length } \\
\text { Effect }\end{array}$ & JND(Length) & $\begin{array}{l}\text { Angle } \\
\text { Effect }\end{array}$ & JND(Angle) \\
\hline $\begin{array}{l}\text { Grating } \\
\text { space }\end{array}$ & $* * *$ & $*$ & $\begin{array}{l}\text { No } \\
\text { sig.dif. }\end{array}$ & No sig.dif. \\
\hline
\end{tabular}

\begin{tabular}{|l|l|l|l|l|}
\hline Sensation & $* * *$ & $* * *$ & $* * *$ & $* * *$ \\
\hline
\end{tabular}

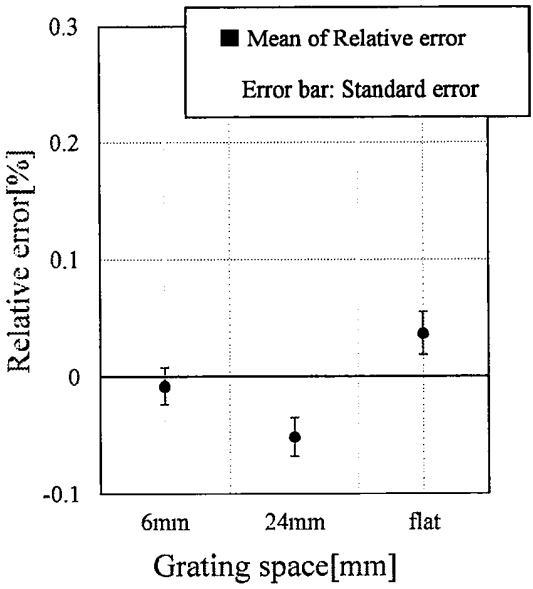

Figure 10 Factor Effect on reproduction errors: Grating space

信号因子の各因子における, 長さ知覚, 角度知覚の系統誤 差に関する分散分析をまとめたものを Table 4に示す. 長さ知覚, 角度知覚ともに, 系統誤差が大きく出ていることが分かる.よっ て, 今後, 長さ知覚, 角度知覚ともに, これら全ての信号因子を 考慮してヒトの系統誤差特性を考える必要がある.

Table 5 ANOVA table on reproduction errors: Signal factor

\begin{tabular}{|l|l|l|}
\hline Signal factor & Length Effect & Angle Effect \\
\hline Angle & $* * *$ & $* * *$ \\
\hline Length & $* * *$ & $* * *$ \\
\hline Speed & $* * *$ & $*$ \\
\hline Subjects & $* * *$ & $* * *$ \\
\hline
\end{tabular}

6. 結言

本研究で得られた結果を以下に示寸゙。

制御因子：

(1) 試験面の長さ知営関しては系統誤差の有意差あり. また, 不等分散性はわずかである.

以上の結果から,グラフより系統誤差の值が小さい「格子面 $6 \mathrm{~mm}$ 水準」が比較的優れた性能を持つことが考えられる.

(2) 感覚因子に関しては系統誤差, 偶然誤差共に $0.1 \%$ 水準で有意

信号因子：

(3) 長さ, 角度知覚共に系統誤差に大きな有意差があ る.

以上の結果から、これら全ての信号因子の系統誤差特性を 考える必要がある.

今後、これらの知覚特性をモデル化することにより知覚の 偏り（系統詔差）を相殺する装置の開発を行っていく.

本研究は, 日本学術振興会科学技術研究費補助金, 挑戦 


\section{文献}

[1] B. L. Whitsel, O. Franzen, D. A. Dreyer, M. Hollins, M. Young, G. K. Essick, and C. Wong, Dependence of Subjective Traverse Length on Velocity of Moving Tactile Stimuli. Somatosensory \& Motor Research, 3(3) (1986), pp. 185-196.

[2] Mei-Fang Cheng, Tactile-Kinesthetic Perception of Length, The American Journal of Psychology, 81(1) (1968), pp. 74-82

[3] R. H. Day and G. C. Avery, Absence of the horizontal-vertical illusion in haptic space. Journal of Experimental Psychology, 83(1-1) (1970), pp. 172-173

[4] F. M. Marchetti, S. J. Lederman, The haptic radial-tangential effect: Two tests of Wong' $s$ "moments-of-inertia" hypothesis, January 1983, Volume 21, Issue 1, pp 43-46

[5] Laura Armstrong and Lawrence E. Marks, Haptic perception of linear extent. Perception \& Psychophysics, 61(6) (1999), pp. 1211-1226.

[6] Susan J. Lederman, Roberta L. Klatzky, and Paul O. Barber, Spatial and movement-based heuristics for encoding pattern information through touch. Journal of Experimental Psychology: General, 114(1) (1985), pp. 33-49.

[7] Henry Faineteau - Edouard Gentaz • Paolo Viviani, The kinaesthetic perception of Euclidean distance: a study of the detour effect, September 2003, Volume 152, Issue 2, pp 166-172

[8] W. Blumenfeld, The relationship between the optical and haptic construction of space Acta Psychologica (Hague), 2 (1936), pp. 125-174.

[9] Lechelt E C, Verenka A, 1980, "Spatial anisotropy in intramodal and cross-modal judgments of stimulus orientation: the stability of the oblique effect" Perception 9(5) $581-589$

[10] Nakayama N, Loomis J M, 1974, "Optical velocity patterns, velocity-sensitive neurons, and space perception: a hypothesis" Perception 3(1) 63-80

[11] F. Vega-Bermudez, K. O. Johnson, and S. S. Hsiao, Human tactile pattern recognition: active versus passive touch, velocity effects, and patterns of confusion. Journal of Neurophysiology, 65(3) (1991), pp. 531-546.

[12]Pierre Wydoodt, Edouard Gentaz, and Arlette Streri, Role of force cues in the haptic estimations of a virtual length. Experimental Brain Research, 171(4) (2006), pp. 481-489.

[13] Kazunori Terada, Akinori Kumazaki, Daisuke Miyata, and Akira Ito, Haptic Length Display Based on Cutaneous-Proprioceptive Integration. Journal of Robotics and Mechatronics, 18(4) (2006), pp. 489-498.

[14] Wouter M. Bergmann Tiest, L. Martijn A. van der Hoff, and Astrid M. L. Kappers, Cutaneous and kinaesthetic perception of traversed distance. Proceedings of the World Haptics Conference (IEEE) (2011), pp. 593-597.

[15] Yoshihiko Nomura, Syed Muammar Najib SYED YUSOH, Ryota SAKAMOTO "Hand-Motion Perception by Four Haptic Modes: Active/Passive and with/without Fingerpad Cutaneous Sensation" Journal of Advanced Mechanical 